\title{
Ciudad y participación vecinal: abordajes teórico- metodológicos para el análisis de organizaciones autoconvocadas $^{*}$
}

\section{City and neighborhood participation: theoretical and methodological approaches for analyzing self-summoned organizations}

\author{
Virginia Cáneva** \\ Universidad Nacional de La Plata, Argentina. \\ vir.caneva@gmail.com
}

Resumen En el presente artículo exponemos un estudio de organizaciones de vecinos autoconvocados. Se caracterizan por ser espacios no instituidos, que emergen en el escenario urbano debido a que sus miembros se sienten interpelados en sus derechos como ciudadanos. Para esta investigación delimitamos como referente empírico la organización Vecinos Autoconvocados de Villa Elisa del partido de La Plata (Buenos Aires, Argentina) creada a partir del rechazo local frente a la posible intervención de una autopista en un barrio de características residenciales. Como una primera exploración, analizamos las características de esas agrupaciones contextualizándolas en el escenario político argentino y las crisis en que se vio sumergido el país. Luego, conceptualizamos dichas características en busca de una definición más acabada de este tipo de expresiones de protesta ciudadana. Finalmente, ofrecemos nuestro desarrollo metodológico y algunas conclusiones.

Abstract In this article we present a study of self summoned neighbors organizations. They are defined as non-instituted spaces that emerge from the urban space because its members feel challenged in their rights as citizens. To this research, we defined as empirical referent the organization "Vecinos Autoconvocados de Villa Elisa" (Self-Organized Neighbors of Villa Elisa) in the Buenos Aires Province, Argentina, created from the local rejection to the possible intervention of a highway in a neighborhood of residential properties. As a first exploration, we analyze the characteristics of these groups. Then, we conceptualize those features in search of a more complete definition of such expressions of citizen protest. Finally, we offer our methodological development and some conclusions.

\section{Palabras} clave

Organizaciones autoconvocadas, comunicación, ciudad, crisis

Key words Self-summoned organizations, communication, city, crisis

\footnotetext{
El artículo se inscribe en el proyecto de investigación "Crisis y reencuentros: la construcción de vínculos intersubjetivos en Vecinos Autoconvocados de Villa Elisa. Una mirada comunicacional sobre la recreación de lazos sociales- urbanos", realizado en el marco de una Beca Doctoral asignada por la Secretaría de Ciencia y Técnica de la Universidad Nacional de La Plata

** Licenciada en Comunicación Social, Laboratorio de Investigaciones de Lazos Socio Urbanos Facultad de Periodismo y Comunicación Social.Universidad Nacional de La Plata.
} 


\title{
1. Introducción
}

\author{
En los años cincuenta y sesenta las ciudades crecieron al amparo de \\ las políticas estatales de integración social y de industrialización. \\ A mediados de los setenta, de la mano de la globalización y la caída \\ de los Estados-nación, vieron acentuarse las desigualdades y la \\ fragmentación. En los últimos tiempos, sin embargo, se han \\ convertido en la sede de nuevas formas colectivas de acción y de \\ discusión de los problemas públicos. \\ "Los nuevos caleidoscopios urbanos", Sidicaro (2004:33).
}

Desde finales de la década de los noventa seasiste, en los países de América Latina, al surgimiento de un amplio y variado conjunto de configuraciones socio-territoriales vinculadas a la defensa del medio ambiente y la soberanía de los recursos naturales (Bonzi, 2010: 197). La emergencia y consolidación de los mencionados espacios de participación vecinal se enmarcan en un contexto de cambios y transformaciones sociales. Podemos dar cuenta en la actualidad de la coexistencia de dos crisis: una de carácter más general, vinculada a la crisis de sentidos que se produce en el tránsito de una manera moderna de vivir y pensar en sociedad hacia una posmoderna, la cual se manifiesta cuando algunos imaginarios que sostenían nuestras sociedades han perdido gran parte de su potencia instituyente (Harvey, 2004; Beck, 1998; Lewkowicz, 2004). La segunda crisis a la que referimos, está relacionada con el agotamiento del neoliberalismo, que siguiendo a Grimson (2008) lo comprendemos no solo como un tipo de política o de modelo económico, sino más bien como una configuración sociocultural.

En Argentina el resquebrajamiento de este modelo se expresó fuertemente en el año 2001, mediante un poderoso cuestionamiento institucional que nos obliga a reflexionar sobre el patrón de funcionamiento de nuestras instituciones, junto al análisis de las reacciones y estrategias adoptadas por la sociedad civil'. Nuestro trabajo propone en este sentido la construcción de una mirada analítica para comprender los fenómenos de participación vecinal que emergen más allá de las asociaciones formalmente instituidas, tomando como espacio principal las organizaciones de vecinos autoconvocados ${ }^{2}$.

1 En palabras de Leiras (2007) la sociedad civil abarca un conjunto amplio de organizaciones con propósitos, historias y formas muy diversas. Para una mirada más completa se recomienda Roitter y González (2000), los autores ilustran la amplitud y diversidad de este conjunto de organizaciones, a partir de una tipología que distingue seis grupos. Tres puros: asociaciones civiles, fundaciones y mutuales, y tres hibridas cooperativas, obras sociales y sindicatos.

2 Las reflexiones que se presentan a lo largo del texto fueron sistematizadas con oportunidad del XI Congreso Latinoamericano de Investigación de la Comunicación "La investigación en Comunicación en América Latina interdisciplina, pensamiento crítico y compromiso social", realizado en Montevideo en el mes de mayo de 2012. La producción formó parte del Grupo de Trabajo Comunicación y Ciudad. 
En nuestra construcción problemática seguimos algunas ideas iniciales que tomaron la forma de hipótesis, las que podemos formular de la siguiente manera: las organizaciones autoconvocadas constituyen espacios de recreación de vínculos cooperativos-solidarios presentes en las instituciones barriales tradicionales como los clubes sociales y deportivos, las sociedades de fomento y las bibliotecas populares; las organizaciones autoconvocadas posibilitan la construcción de ciudadanía, rompiendo con el ostracismo social incentivado por las políticas neoliberales; las organizaciones de vecinos autoconvocados facilitan la reconstrucción del diálogo entre los ciudadanos y el Estado.

La relación entre las instituciones tradicionales barriales y las organizaciones de vecinos autoconvocados responde a un recorrido de investigaciones en las cuales se buscó problematizar los modos en los que ambos espacios crean y recrean lazos sociales. Como primeros antecedentes situamos el proyecto de investigación "Clubes sociales, hangares vacíos o potenciales espacios de construcción y reconstrucción de vínculos intersubjetivos" y la tesis de grado "Clubes platenses al rescate de lo colectivo" ${ }^{\text {" realizada }}$ en coautoría con el licenciado Hernán Mendoza. Tales trabajos se desarrollaron a partir del estudio del proceso de gestación y actual significación de los clubes sociales de la ciudad de La Plata, con el fin de indagar qué potencialidades invisten como espacios de reconstrucción y consolidación de lazos urbanos.

\section{De la institución a la autoconvocatoria vecinal}

Como resultado de esas indagaciones asumimos que, si bien en la actualidad podemos observar un resurgimiento en la participación de los vecinos en las instituciones tradicionales de su barrio, es innegable que el papel central que ocupaban las asociaciones de inmigrantes, los clubes sociales y deportivos, las sociedades de fomento y las bibliotecas

\footnotetext{
3 El mencionado proyecto se inició en el año 2006 y concluyó en diciembre de 2009, fue dirigido por la Doctora María Eugenia Rosboch, en el marco del Programa de Incentivos a la Investigación y la Docencia del Ministerio de Educación de la Nación Argentina. Participé de este proyecto desde sus inicios, incorporándome como investigadora en formación cuando estaba finalizando las últimas materias de la Licenciatura en Comunicación Social. Durante los años 2008 y 2009 participé del proyecto como graduada.

4 La tesis se desarrolla a partir del cuestionamiento acerca de la situación que atraviesan en la actualidad los clubes sociales platenses. Teniendo en cuenta la importancia que históricamente tuvieron como espacios de creación y recreación de lazos sociales urbanos, nos preguntamos: ¿Qué lugar ocupan hoy los clubes en la ciudad y qué rupturas y continuidades se producen con la irrupción de la posmodernidad? Se reconstruyen tres etapas principales en la historia de los clubes: un momento de surgimiento; una época de esplendor y un periodo de deterioro, vinculado a cambios culturales asociados al pasaje de un modelo de pensar y vivir la sociedad a otro relacionado con imaginarios y representaciones de la posmodernidad. Por otro lado, rastreamos las reacciones o estrategias que desde los clubes se presentan para hacer frente a este momento de crisis. Observamos como penetra en el club la lógica de consumo y cuáles son las subjetividades que se recrean. De esta manera, intentamos esbozar cuáles son las posibilidades que tiene el club, como institución barrial, para reconstruir vínculos con la comunidad.
} 
populares ya no es el mismo (Cáneva y Mendoza, 2007). Los espacios mencionados nacen como institución junto al proceso de consolidación del Estado argentino, que en el caso de la ciudad de La Plata se vincula además de manera directa con su fundación en el año 1882.

Posteriormente, estas instituciones fueron construyendo su lugar de privilegio en la vida de cada uno de los barrios. En su etapa de esplendor (1930-1960) el club social se presentaba como el escenario por el cual pasaba toda la actividad barrial: la diversión, el deporte, la cultura, la discusión, los debates públicos y las fiestas. El momento de popularización de los clubes en Argentina se relaciona con procesos históricos en los cuales el Estado y las instituciones en general gozaban de una solvencia y un prestigio que hoy parecen cuestionados. Nos referimos a una época donde lo público y sus instituciones se conceptualizaban como propiedad comunal, contrastando con la actualidad donde "lo público" se establece en oposición a "lo privado" (Lewkowicz, 2004; Rosboch y Cáneva, 2010). En el nivel barrial, estos valores redundaban en la ilusión y la confianza de todos en la posibilidad de trabajar juntos por el progreso y el mejoramiento de la calidad de vida de la comunidad. Los clubes sociales constituían también un escenario privilegiado para el ejercicio de la participación comunitaria y ciudadana.

Entre las décadas de 1960 y 1970 el club empieza a transitar su etapa de deterioro, cuando en el país comienzan a implementarse políticas neoliberales en manos de gobiernos dictatoriales que contribuyeron al repliegue de la sociedad al ámbito de lo privado, a través de mecanismos fuertemente represivos. Como consecuencia de estas transformaciones culturales, sociales, políticas y económicas, los espacios públicos tradicionales retroceden. Es en este sentido que resulta pertinente indagar qué ocurre en la actualidad con los lugares que antaño canalizaban la demanda ciudadana y qué espacios son los que hoy la posibilitan.

A nuestro entender, ese lugar lo captan, en parte, agrupaciones sociales autoconvocadas que a partir de diferentes demandas de la sociedad rompen con el ostracismo cívico, incentivado por políticas neoliberales que fomentan el repliegue al ámbito de lo privado, generando en el tejido social compromiso y participación ciudadana a partir de la construcción de espacios intersticiales de debate y discusión. Siguiendo ese interés, comenzamos a trabajar en el año 2010 en el proyecto "Del ostracismo social a la construcción colectiva. La configuración y reconfiguración de espacios urbanos de 
participación ciudadana"5. La propuesta fue entonces sumar al estudio de los clubes sociales, espacios que ocupan en la actualidad el lugar abandonado por esas instituciones barriales. En este marco se construye el proyecto de tesis doctoral "Crisis y reencuentros: la construcción de vínculos intersubjetivos en organizaciones de vecinos autoconvocados" ${ }^{\text {. }}$

Recuperando las reflexiones sobre el contexto actual, vale puntualizar que la década de 1970 marca un momento de crisis y quiebre respecto del rol que cumplirá el Estado durante el último cuarto del siglo XX en los países de la región. La implementación de políticas de ajuste estructural 7 , iniciada principalmente a mediados de los años ochenta y profundizada durante los años noventa, tendrá un importante impacto en el funcionamiento de las tramas y estructuras sociales, en la intervención del Estado en la economía y en la implementación de nuevas políticas públicas. El debilitamiento del Estado de Bienestar con el arribo del neoliberalismo en manos de gobiernos dictatoriales marcó "un punto de no retorno, el fin de un determinado tipo de sociedad. Hasta entonces la sociedad argentina había sido relativamente integrada, en ella había surgido una importante clase media" (Kessler y Di Virgilio, 2008: 32). El resultado de este proceso es un extendido fenómeno de pauperización social, que se refleja en el deterioro del nivel de vida de grandes sectores de clase media, la desarticulación del mercado de trabajo y los cambios en el sistema previsional. Al mismo tiempo, las consecuencias de una nueva agenda política se observan en otras instancias como la desregulación del servicio público, la penetración de capitales extranjeros para la explotación del suelo y los recursos naturales, como así también, cambios en los estatutos de defensa y conservación del medio ambiente.

En respuesta a estas transformaciones, se erigen grupos de vecinos autoconvocados, organizaciones que surgieron como forma de resistencia a la instalación de corporaciones mineras en diferentes puntos del territorio nacional (Bonzi, 2009; Svampa y Sola, 2010;

5 El proyecto es dirigido por la Doctora María Eugenia Rosboch y se enmarca en el Programa de Incentivos a la Investigación y la Docencia del Ministerio de Educación de la Nación. Las tareas de investigación comenzaron en enero de 2010 y finalizaron en diciembre de 2011.

6 El mencionado proyecto de tesis fue aprobado por el Comité Académico de la carrera de Doctorado en Comunicación de la Facultad de Periodismo y Comunicación Social de La Plata por Resolución № 2700-5737. En paralelo al desarrollo de mis estudios de posgrado participé como investigadora del proyecto "Citas urbanas: Construcción y regeneración de lazos socioculturales en la ciudad". Las tareas se iniciaron en enero de 2012 y continuaron hasta diciembre de 2013, el proyecto fue dirigido por la Doctora María Eugenia Rosboch, mi participación se vincula con las tareas propuestas para el tercer año de Beca de Iniciación otorgada por la UNLP.

7 Joseph Ramos (1997) en su "Balance de las reformas estructurales neoliberales en América Latina" agrupa en siete las principales transformaciones implementadas por los estados: las políticas anti-inflacionarias y de ajuste, la reforma tributaria, la apertura comercial, la liberalización financiera, las privatizaciones, los cambios del sistema previsional y las reformas del mercado de trabajo. 
Weinstock, 2012; Claps y Colao, 2005). Este modo de organización rebasó las fronteras locales y se convirtió en una posible manera de congregar vecinos para promover discusiones, propuestas y luchas sobre los más variados temas. En el distrito de La Plata, donde se encuentra la ciudad capital de la provincia de Buenos Aires, existen numerosas organizaciones vinculadas con la defensa del patrimonio, los espacios verdes, la seguridad vial, el desarrollo sustentable, la preservación del medio ambiente, el tratamiento de los residuos y la urbanización en los barrios de la periferia.

La crisis económica, política y social desatada en el año 2001 dejó en claro que el patrón de funcionamiento de las instituciones democráticas no aseguraba la inclusión social y política, la participación y la representación efectiva de grandes porciones de la población. En un contexto de rechazo a la clase política en su conjunto surgieron, como una forma innovadora de activismo de sectores de clase media, las asambleas populares. Este fenómeno significó la consolidación de espacios barriales para ejercer formas deliberativas de democracia directa. Los vecinos integrantes de estas organizaciones comenzaron a reunirse para discutir e intervenir tanto en cuestiones vinculadas con la política nacional, como en acciones para paliar las necesidades urgentes de cada barrio. En marzo de 2002 existían 329 asambleas en el país y cada una de ellas congregaba un promedio de alrededor de cien participantes (Freidín y Perugorría, 2007). La ciudad de Plata no fue ajena a este proceso de conformación del movimiento popular asambleario y en el año 2002 cada barrio platense contaba con su propia asamblea. Estas organizaciones emergieron en la ciudad por causas variadas y en momentos diferentes. El factor común que compartieron las asambleas fue su carácter de autoconvocadas.

Los vecinos autoconvocados son organizaciones territoriales que se constituyen como actores, en tanto participan de una disputa por la forma que adoptará su territorio tanto en términos materiales como simbólicos. En palabras de Pedro Pírez (1995), los componentes sociales urbanos se fijan en la relación entre dimensiones sociales y territoriales: "Si bien los actores urbanos dependen de los procesos estructurales, el papel que juegan en la ciudad depende de la forma particular en que se organicen como unidades de acción y ello depende también de su relación con el territorio urbano" (1). La trama de la urbe se presenta así como una obra que, si bien se basa en contradicciones estructurales, no parece estar determinada por ellas, sino que depende de los papeles que juegan los diferentes actores que se vinculan con ella. 
A partir de lo expuesto nos propusimos indagar: qué lugar ocupan las organizaciones autoconvocadas en tanto espacios de construcción de lazos sociales urbanos; cuál es su presencia en el espacio público actual; qué rupturas y continuidades se pueden encontrar entre estas agrupaciones y los tradicionales espacios de construcción de lazos urbanos, como los clubes sociales y deportivos, las sociedades de fomento o las bibliotecas populares.

En las próximas secciones presentamos diferentes decisiones vinculadas con la construcción del referente empírico de nuestro trabajo, Vecinos Autoconvocados de Villa Elisa (en adelante V.A.V. E.), la construcción de una categoría analítica a partir de relecturas clásicas -y no tan clásicas- sobre la construcción de espacios alternativos a los formalmente instituidos, y herramientas clave de nuestra estrategia metodológica, que facilitan el abordaje de prácticas dinámicas de participación vecinal.

\section{Relecturas y apropiaciones para la conceptualización de vecinos autoconvocados}

El estudio de las organizaciones autoconvocadas en tanto fenómeno social y cultural dinámico requiere de esfuerzos para su descripción y análisis. En la actualidad, identificamos dos enfoques vigentes: por un lado, observadores que definen los encuentros sociales actuales como "resurgimiento", "reemergencia", "renacimiento o reconstrucción"; al mismo tiempo, algunos analistas rechazan esas etiquetas, para ellos la ampliación de la arena política no es una reedición de patrones conocidos previamente sino un fenómeno en el que predominan los rasgos novedosos (Leiras, 2007).

Posicionados en el marco de la primera perspectiva proponemos entender las configuraciones sociales y culturales como continuidades. En este sentido, retomamos los estudios de Raymond Williams (1997) que proponen comprender las complejas relaciones de poder, características del capitalismo avanzado, prestando atención a los elementos residuales, los componentes marginados de la tradición selectiva y los rasgos que se presentan como emergentes. Esta línea nos permite acercarnos al fenómeno de las organizaciones autoconvocadas comprendiendo que los procesos de construcción hegemónicos se dan por medio de la conexión de diferentes formas de lucha que van más allá de lo meramente político y económico.

Este ejercicio de revisar qué elementos del pasado y qué rasgos novedosos se observan en las organizaciones autoconvocadas nos abre el camino para el análisis de la creación y recreación de prácticas culturales y sociales vinculadas con la participación política. 
Proponemos la categoría de formaciones como punto de partida para dirigir nuestra mirada hacia esos espacios barriales y territoriales que se encuentran por fuera del entramado institucional tradicional, como los clubes sociales y deportivos, las sociedades de fomento o las sociedades de inmigrantes. Williams define a las formaciones como:

"los movimientos y tendencias efectivos, en la vida intelectual y artística, que tienen una influencia significativa y a veces decisiva sobre el desarrollo activo de una cultura y que presentan una relación variable y a veces solapada con las instituciones formales" (1997:139).

Al apropiarnos de esta definición, advertimos un vínculo estrecho con las manifestaciones y tendencias artísticas e intelectuales. Comprender el arte, la cultura y las ideas con una mirada anclada en las relaciones de poder subyacentes nos permite adentrarnos en el estudio de los procesos de lucha por la inclusión de la ciudadanía. Esas prácticas se materializan tanto en el accionar de las instituciones como en los proyectos, programas y propuestas que emergen en espacios no instituidos formalmente, como las organizaciones de vecinos autoconvocados.

Tomando como punto de partida la crisis del Estado Benefactor, René Millán (1994) propone el término organizaciones voluntarias asistencialistas para referirse a la formación de grupos de apoyo, que llevan adelante políticas sociales con modalidades muy heterogéneas y en inserciones institucionales diversas. Estas formaciones no son nuevas, pero se produce una importante difusión de estas "microsolidaridades", junto al proceso de transformaciones y reformas que sufrieron los Estados. El resurgimiento de estos espacios rompe con la lógica binaria que argumenta que el Estado o el mercado son los ámbitos a partir de los cuales se generan políticas de solidaridad. Al mismo tiempo, estas miradas desconocen o desvalorizan apresuradamente las maneras de construir lazos de solidaridad de formas microsociales que "presentan un carácter innovador en su función cultural, en la vinculación entre participación e individualidad y en su inserción en la estructura institucional" (1994: 66). Los aportes de esta perspectiva nos permiten agudizar la mirada acerca de los lazos que tejen los sujetos, el vínculo entre lo público y lo privado y reforzar nuestra inquietud sobre los rasgos innovadores y los entramados institucionales de las organizaciones autoconvocadas.

Por su parte Rossana Reguillo (1999) denomina a esas organizaciones como grupalidades, entendiéndolas como la emergencia de formas de agrupación social no partidarias y no institucionalizadas, que erosionan desde las márgenes del sistema, alterando las maneras 
de ejercicio del poder. Este fenómeno tiene lugar en un contexto en el cual -según la autora- el sindicato, el partido, la asociación, crecen como formas corporativas de control, pero disminuyen como espacios de referencia y de adscripción. En paralelo a este proceso: "se asiste a la multiplicación de pequeños grupos que desbordan las categorías científicas en la medida en que no se inscriben en una racionalidad orientada y finalizada" (Reguillo, 1999: 88). Al mismo tiempo la autora observa que las grupalidades son de composición cambiante, de inscripción local y de estructura cotidiana, y tienden a interrelacionarse de manera horizontal, sin mediación del Estado, con otras colectividades.

Consideramos innegable el aporte que implica la noción de grupalidades al posicionar las agrupaciones en el entramado de las relaciones de poder (aspecto que no se observa en Millán). Retomamos también su contribución para reflexionar acerca de las categorías analíticas con las que contamos, cuando las finalidades del encuentro no las propone una institución sino la sociedad misma de manera espontánea y no institucionalizada. Por último, retomamos su mirada acerca de la política comprendida más allá de la práctica o militancia partidaria.

Por lo expuesto, el camino que recorrimos nos permitió construir una categoría capaz de dirigir nuestra mirada hacia el estudio de los vínculos intersubjetivos, que se crean y recrean al interior de formaciones ubicadas por fuera de una trama institucional tradicional. Valorar y analizar la espontaneidad del encuentro social, repensando la relación entre lo público y lo privado, cuando lo que convoca no es ya la institución sino los propios vecinos, nos posibilitó marcar la distancia institucional con el gobierno, partidos políticos o cualquier institución que se desprenda de esas entidades, y comprender la participación política como una práctica que rebasa las fronteras de la participación anclada en un partido político. Por último, nos abrió el camino para observar y estudiar el carácter territorial, local y barrial que adquieren estas configuraciones y su potencialidad para construir estrategias de representación en el espacio público, al tiempo que nos advirtió sobre los múltiples modos que adquieren los procesos de lucha por la inclusión y la ampliación de la participación ciudadana.

\section{Construcción metodológica}

Hasta aquí compartimos con el lector la construcción de una mirada problemática que busca comprender los modos de estar juntos de los actores sociales en momentos de crisis 
y tránsito. Dentro de los múltiples modos de encontrase de la sociedad civil, propusimos anclar nuestra mirada en las actuales organizaciones de vecinos autoconvocados. Definimos para ello la realización de un estudio de caso, que busca comprender el fenómeno a partir del análisis de la organización Vecinos Autoconvocados de Villa Elisa. Posteriormente, recuperamos un ejercicio de construcción conceptual, que nos permite dirigir nuestra mirada a esos espacios emergentes que se desarrollan por fuera de las tramas institucionales formales, sean estas de raigambre barrial, dependientes del Estado, de organizaciones políticas o sindicales.

En las próximas páginas presentamos una serie de decisiones metodológicas que posibilitan el abordaje de fenómenos de participación dinámicos. Para iniciar este ejercicio comenzamos por exponer una perspectiva de análisis que, anclada en el campo de la comunicación/cultura, dirige nuestra mirada al ámbito de las prácticas y las interacciones cotidianas de los actores, espacios propicios para comprender la producción de sentidos que se crean el interior de las organizaciones de vecinos autoconvocados.

Los Estudios en Comunicación emprendidos desde un abordaje político cultural (Torrico, 2004) abren el camino hacia el análisis y el conocimiento de las mediaciones y múltiples mediaciones, las polisemias de los mensajes y la recepción crítica, la relación de la vida cotidiana con las tecnologías, las prácticas de microresistencia, los frentes culturales y el consumo cultural. Nuestro trabajo retoma algunas de estas perspectivas al problematizar la construcción de lazos sociales, los modos de agrupación de la sociedad civil, la consolidación de identidades sociales y dinámica de la relación entre los ciudadanos y el Estado. Es a partir de esta mirada que proponemos dar cuenta de procesos de cambios y transformaciones como los asociados con la reconfiguración del Estado y sus funciones tradicionales, los imaginarios y representaciones acerca de los ciudadanos y la participación política. Además de considerar las inquietudes actuales que permiten la formación de nuevas grupalidades (Reguillo, 1999) y las transformaciones en el tejido urbano de las ciudades contemporáneas.

La perspectiva teórica comunicacional que proponemos invita a pensar a la comunicación desde las prácticas cotidianas de los sujetos. En este sentido, resulta imposible separar la comunicación del proceso de construcción y consolidación de las identidades sociales, ya que es a partir de esta producción, reproducción y transformación de sentido que toman forma las interacciones, las relaciones de poder, y los espacios de intercambio y conflicto. 
La comunicación aparece entonces como una instancia de diálogo, de puesta en común, de relaciones de fuerza y, por lo tanto, de negociación (Martín-Barbero, 1987; GarcíaCanclini, 1990).

En líneas generales este abordaje se corresponde con una perspectiva metodológica que, anclada en las ciencias sociales, persigue la intencionalidad de comprender la realidad social que estudia y no la de comprobar o verificar dimensiones previamente definidas sobre ella. El trabajo se lleva a cabo desde el marco teórico-metodológico cualitativo, entendiendo que este modelo permite el abordaje del objeto de estudio desde una postura reflexiva e interpretativa de las acciones humanas.

A continuación sintetizamos algunas de las decisiones vinculadas a las tareas realizadas en la etapa de recolección de datos (Piovani, 2007). Para esta investigación las actividades relativas a la recolección de datos fueron iniciadas a finales del año 2010, período en el que delimitamos nuestro referente empírico: la organización Vecinos Autoconvocados de Villa Elisa. La localización, descripción y acercamiento a las diferentes organizaciones autoconvocadas del distrito de La Plata nos ayudó a realizar este recorte, al tiempo que nos permitió dar cuenta de la magnitud de la problemática estudiada. Las técnicas que se utilizaron fueron entrevistas a los autoconvocados, lectura de diarios locales, interacción con las organizaciones a partir de sus redes sociales Facebook y Twitter, recopilación de información disponible en el Centro Comunal de Villa Elisa, la Biblioteca Alejo Iglesias de la misma localidad y la Federación de Instituciones Culturales y Deportivas de La Plata. Esta tarea posibilitó:

- Recoger información valiosa para comenzar a establecer diferencias, similitudes, rupturas y continuidades entre las organizaciones autoconvocadas, y otros ámbitos de vinculación entre los sujetos como los clubes de barrio, sociedades de fomento y bibliotecas populares.

- Analizar momentos de mayor auge de organizaciones como la década de los noventa y la crisis post 2001.

- Reflexionar sobre los diferentes intereses presentes en la ciudadanía y la construcción de espacios alternativos para canalizar sus demandas.

Otra de las actividades realizadas en esta etapa fue el seguimiento del tema en los medios locales. Esta actividad se ejecutó a partir de la recopilación, lectura y análisis de las 
publicaciones digitales de los diarios locales y de la región. El corpus fue confeccionado a partir de los buscadores de los portales de los propios diarios y de las actualizaciones que las agrupaciones realizan en sus interacciones en plataformas como Facebook y Twitter. En el marco de la investigación las notas son construidas como fuentes secundarias y con los datos obtenidos se confeccionaron cuadros donde se puntualizan: el medio, el título, la página donde está disponible, los actores, actividades, temas y testimonios relevantes ${ }^{8}$. Esta labor nos permitió:

- Rastrear organizaciones anteriores a la formación del grupo de V.A.V.E.

- Construir un mapa de las instituciones tradicionales de V.A.V.E.

- Recuperar las actividades de los vecinos realizadas con anterioridad al inicio del trabajo de campo.

- Conocer documentos, especialistas y organismos involucrados en la problemática.

- Complementar las observaciones realizadas en el trabajo de campo.

- Recuperar discursos de los vecinos protagonistas.

- Identificar actores implicados en la problemática y ordenar cronológicamente las diferentes etapas del conflicto.

En paralelo a esta tarea, se compilaron y analizaron documentos, mapas, discursos y textos producidos por los diferentes actores vinculados de manera directa o indirecta con la problemática. Estas acciones posibilitaron comprender los alcances económicos, políticos y territoriales de los diversos actores implicados e inferir el poder que ejercen los diferentes sujetos y su incidencia en las decisiones que se toman. De este modo, delimitamos actores nacionales, provinciales, locales, instituciones, partidos políticos y empresas. Al mismo tiempo, este material contribuyó a la producción de una línea cronológica sobre los acontecimientos. Por último, la lectura de mapas abrió el camino para comprender el escenario no solo desde su aspecto físico, sino también desde su ubicación en el entramado urbano local y regional.

Una vez seleccionado nuestro referente empírico, definimos por un lado "la unidad de estudio" compuesta por el ámbito físico y, por el otro, las "unidades de análisis" integradas

8 La construcción de esta fuente de información formó parte de todo el período de investigación. El corpus de las notas está integrado por 178 artículos publicados en las plataformas digitales de los diarios platenses El Día (116 artículos), Hoy (15) y Diagonales (9); en las agencias de noticas Infoplatense (3), Infu -revista digital de la zona norte- (10), Real Politik (2), Diario Judicial (2), La Política Platense (2), Info Villa Elisa (3), Infocielo (1) y Agencia Nova (2); y en medios de difusión de alcance nacional como los diarios Clarín (3), Pagina 12 (1), La Nación (5) y Perfil (2). 
por los sujetos de estudio (Guber, 2008). Siguiendo esta propuesta se construyeron como unidades de estudio las reuniones de los vecinos, los territorios por ellos recorridos y las actividades propuestas. Las unidades de análisis fueron divididas en dos: unidades de análisis privilegiadas, los sujetos vinculados de manera directa con la agrupación, y unidades de análisis secundarias, aquellos actores sociales relacionados de manera indirecta con la organización de vecinos autoconvocados. Inicialmente, la técnica más utilizada fue la observación participante. El registro de las actividades, como reuniones grupales, participaciones públicas, intervenciones directas en el escenario de la ciudad, se materializó en notas de observación y en la grabación/des-grabación mediante la utilización de dispositivos de audio. Este ejercicio permitió obtener mayores detalles, principalmente en lo referido a la interacción de los actores, sus diálogos y alocuciones. La participación en las actividades favoreció para la construcción de las siguientes dimensiones:

- Situar alcance del conflicto en la dimensión local y reconocer organizaciones aliadas del grupo autoconvocado.

- Registrar las formas de participación propias del grupo y las tensiones y/o desacuerdos con otros modos de organización vinculados con la misma lucha.

- Identificar actores representativos y referentes grupales, dando cuenta de posiciones diferenciadas o relaciones de jerarquía; reconocer las motivaciones que llevan a la acción colectiva y los acuerdos que posibilitaron la acción grupal.

- Recuperar tensiones y puntos de conflicto al interior del grupo y con las organizaciones aliadas; apuntar instituciones tradicionales de la localidad de Villa Elisa y describir los diálogos y relaciones que el grupo les propone.

- Identificar la apropiación de la ciudadanía que el grupo realiza y las representaciones que construyen sobre el sistema democrático y la relación con sus representantes; reconocer objetivos políticos en el corto y el mediano plazo.

- Dar cuenta de las actividades que forman parte de la estrategia de acción; problematizar la relación que entablan con los medios de comunicación; construir lazos con los actores y seleccionar informantes clave.

Una segunda herramienta que resultó fundamental tanto en el acercamiento como en el desarrollo del trabajo de campo, fue la realización de entrevistas semi-estructuradas. Para delimitar la muestra se seleccionaron a miembros de V.A.V.E como informantes clave y se recurrió a la técnica de la entrevista, considerando a ésta como la situación de interacción social que se establece entre el entrevistado y el entrevistador, que posibilita 
la construcción de discursos sobre las percepciones, miradas y evaluaciones de los sujetos involucrados en los hechos que se estudian. La entrevista se define así como un constructo comunicativo en el que entran en juego los marcos interpretativos del entrevistado y del entrevistador.

Las entrevistas realizadas no fueron estructuradas según un cuestionario sino que, por el contrario, se pensaron y elaboraron tópicos como estímulo para guiar las reflexiones de los actores. Freidín y Perugorría (2007) conceptualizan a las entrevistas semiestructuradas e inestructuradas como herramientas que "facilitan la exploración de las maneras en las cuales las personas otorgan sentido a su participación en acciones colectivas e interpretan la trayectoria del movimiento" (216). Al mismo tiempo, estas entrevistas permiten observar los alineamientos entre identidades individuales y colectivas que favorecen el análisis de las emociones que originan y permiten dar cuenta de la multiplicidad de perspectivas existentes entre sus miembros.

Los tópicos que formaron parte del momento de la entrevista fueron elaborados a partir de los siguientes ejes:

- Histórico-local: Villa Elisa, orígenes fundacionales y actualidad, tensiones ruralidad/ ciudad, trabajadores tradicionales/profesionales.

- Instituciones locales y trayectoria instituida: participación y/o conocimiento de instituciones barriales de Villa Elisa, representaciones sobre la crisis de lo institucional.

- Autoconvocatoria vecinal: motivaciones personales, formación de V.A.V.E.

- Conformación de V.A.V.E.: antecedentes, relaciones con organizaciones e instituciones, diálogos posibles.

- Prácticas de ciudadanía: relación con representantes (nacionales, provinciales, municipales), estrategia de acción, experiencia de gestión, espacio de expresión y autorepresentación.

- Capitalización de la experiencia: cambios en la percepción del espacio, ciudad, el Estado y las instituciones.

- Continuidad: logro de objetivos, continuidad de la organización (cambio de objetivos), surgimiento de otros espacios de participación ciudadana (qué otros reclamos protagonizar como ciudadanos). 
Cada una de las instancias de encuentro fue particular y los tópicos fueron desarrollados de manera diferenciada según el perfil de cada uno de los entrevistados. Realizamos un total de diez entrevistas, durante los meses de noviembre de 2012 y julio de 2013, que recopilan la diversidad de actores que forman parte de V.A.V.E.

Es necesario aclarar que las actividades mencionadas no se realizaron de manera cronológica siguiendo un orden preestablecido, sino que se estableció un diálogo permanente entre las diferentes instancias de recolección y de análisis de datos. Finalmente, la técnica para sistematizar el material obtenido es el análisis interpretativo utilizando técnicas de procesamiento manual.

\section{Estudio de caso de Vecinos Autoconvocados de Villa Elisa.}

Vecinos Autoconvocados de Villa Elisa nace en el año $2010^{9}$ cuando la comunidad local toma conocimiento de la existencia de un proyecto por el cual el tramo IV de la Autopista Presidente Perón podría construirse sobre la calle 403 de esa localidad y comienzan a reunirse con el fin de oponerse a la propuesta. Villa Elisa es una ciudad que pertenece al distrito de La Plata ${ }^{10}$, se encuentra a 12 kilómetros de la ciudad cabecera y capital de la provincia de Buenos Aires y a 30 de la Ciudad Autónoma de Buenos Aires. Es posible ubicarla dentro de las ciudades intermedias, según los registros del Censo Nacional 2010 cuenta con 22.243 habitantes (INDEC, 2010).

En perspectiva regional, la propuesta de construcción de la Autopista de Vinculación Presidente Perón que Vialidad Nacional diseñó da cuenta de cambios, transformaciones y tendencias en la organización territorial de la región. Un área geográfica que, desde el proyecto de organización nacional, momento histórico en el cual la Argentina se

9 Es importante aclarar que si bien esta organización hereda sentidos de las agrupaciones surgidas con posterioridad a la crisis del 2001, su contexto de emergencia es significativamente diferente. En términos generales, la institucionalidad del país logró estabilizarse, y a casi diez años del grito popular "que se vayan todos" el kirchnerismo como fuerza política cumplía su séptimo año en el gobierno.

10 La provincia de Buenos Aires se compone de 135 partidos. Según se expresa en el Artículo 190 de la constitución provincial, "la administración de los intereses y servicios locales en la Capital y cada uno de los partidos que formen la Provincia, estará a cargo de una Municipalidad, compuesta de un departamento ejecutivo unipersonal y un departamento deliberativo, cuyos miembros, que no podrán ser menos de seis ni más de veinticuatro, durarán cuatro años en sus funciones, renovándose cada dos años por mitad y serán elegidos en el mismo acto que se elijan los senadores y diputados, en la forma que determine la ley". En la organización administrativa de cada municipio se encuentra una ciudad cabecera donde reside el Poder Ejecutivo Municipal y localidades en las que cuenta con Centros Comunales. El partido de La Plata cuenta con la ciudad homónima como cabecera y los Centros Comunales de: Villa Elvira, Tolosa, Ringuelet, Manuel B. Gonnet, José Hernández, Joaquín Gorina, Los Hornos, San Carlos, City Bell, Altos de San Lorenzo, Villa Elisa, El Peligro, Arturo Seguí, Melchor Romero, Abasto, Lisandro Olmos, Ángel Etcheverry y Eduardo Arana. 
consolida como Estado nacional moderno, adquirió una centralidad económica, política y administrativa que privilegió a la Capital Federal y su zona más cercana por sobre otras regiones del país. Sin embargo, el crecimiento de ésta área no ha sido homogéneo y muestra fuertes desigualdades entre los diversos distritos que la componen y también hacia el interior de los mismos.

Los municipios que la traza de la Autopista Perón tiene previsto recorrer forman parte del Conurbano Bonaerense ${ }^{11}$, el área geográfica más poblada del país, que según los datos publicados por el último censo poblacional realizado en el año 2010 albergaba a 9.916 .715 personas (INDEC, 2010). La concentración de la población en el área metropolitana responde a procesos históricos y decisiones políticas de larga data.

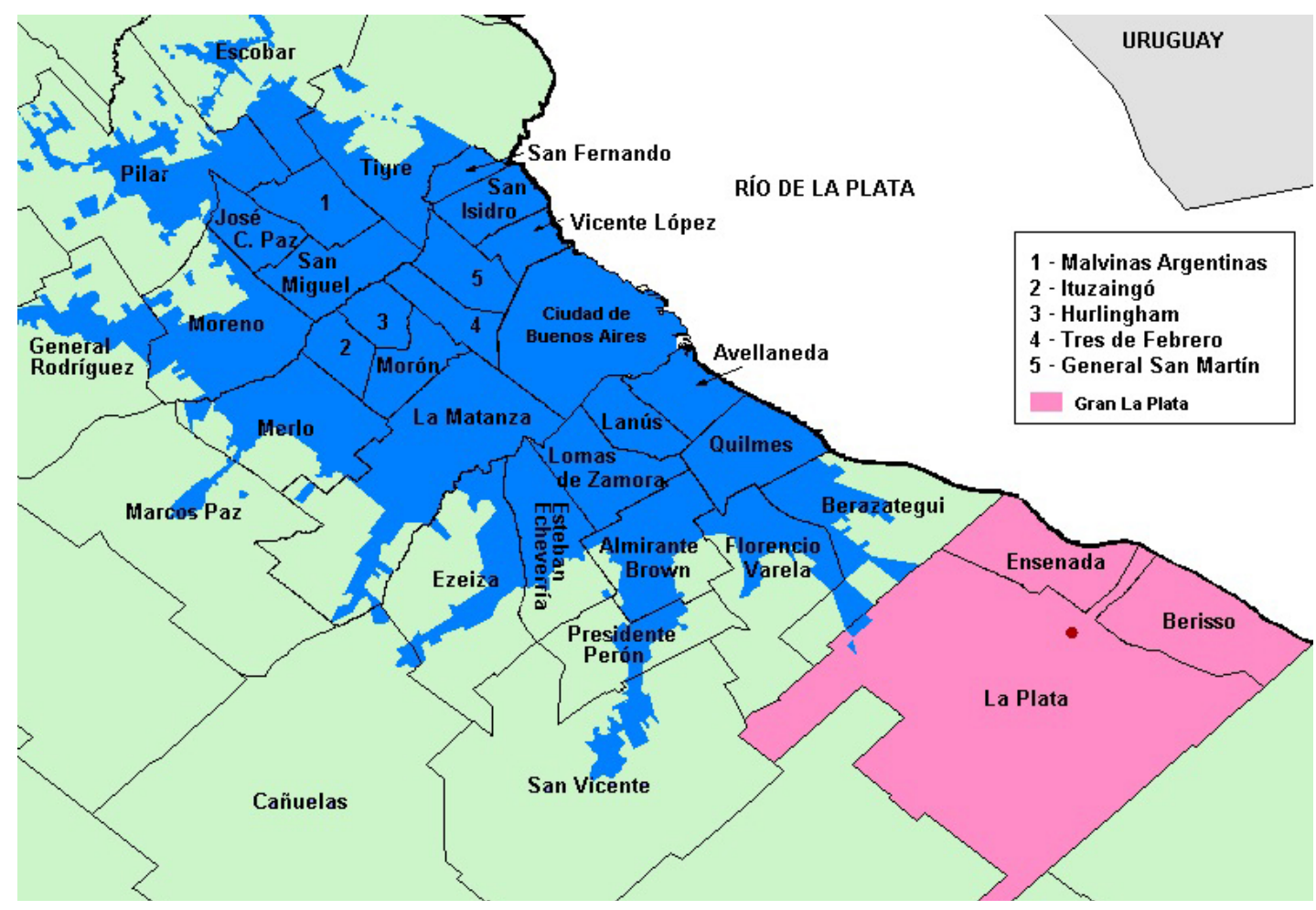

Figura No 1: Ubicación de los partidos del Gran Buenos Aires y el Gran La Plata en la Región Metropolitana de Buenos Aires. Fuente: commons.wikimedia.org

11 Con el transcurrir de los años, las diferentes administraciones de la provincia buscaron delimitar esta área, sobre todo para implementar diversos programas de intervención. A los fines de este trabajo, subrayamos una de sus múltiples demarcaciones, que delimita el área del Conurbano Bonaerense con el objetivo de vehiculizar programas y políticas públicas. Los diferentes gobiernos fueron sumando municipios, hasta llegar a contener hoy a la Ciudad Autónoma de Buenos Aires junto con treinta y tres distritos municipales bonaerenses. La Plata forma oficialmente parte de esta área desde la promulgación de la Ley 11746/96, que incorpora la distribución diseñada en 1994, conformando junto con las localidades vecinas de Ensenada y Berisso, la denominada Microrregión del Gran La Plata, de aproximadamente 705.000 habitantes (Frediani, 2010). 
Por otra parte, es pertinente explicitar que el proyecto vial se encuadra en un contexto de trasformaciones sobre la región donde destaca la planificación y ejecución de obras como: la construcción de una terminal de contenedores portuaria en la ciudad de Berisso, la ampliación de la traza de la autopista Buenos Aires-La Plata, la construcción de un cableado de alta tensión entre los partidos de Ensenada y Berazategui y el restablecimiento del aeropuerto local en la ciudad capital de la Provincia. Al mismo tiempo, otro factor que incide en la reorganización territorial de toda la zona son las inversiones inmobiliarias, que impulsaron al gobierno municipal a presentar un conjunto de ordenanzas que introdujeron importantes cambios en el Código de Ordenamiento Urbano y en el Código de Edificación. Ambas modificaciones se aprobaron en abril de 2010², luego de varios meses de agitadas discusiones donde surgieron voces opositoras provenientes de diferentes sectores de la ciudadanía.

Volviendo al origen del conflicto, la realización de la obra es impulsada por el Gobierno Nacional como continuación del Camino del Buen Ayre y busca convertirse en el tercer anillo que rodea al Área Metropolitana de Buenos Aires, con el fin de conectar catorce distritos. El proyecto, según se explica desde el Ministerio de Planificación de la Nación, tendrá una traza de 117 kilómetros divididos en cuatro tramos. El primero será de 23 kilómetros y comenzará en el Camino del Buen Ayre hasta la entrada en el partido de La Matanza. El segundo comprenderá desde la localidad matancera de 20 de Junio hasta la ruta 53, el tercero hasta el cruce con la ruta provincial 58 y el último irá desde ese mojón hasta la autopista Buenos Aires-La Plata.

El enlace vial tiene proyectadas varias trazas posibles para su última etapa de ejecución. Dos de ellas, en palabras de los vecinos movilizados, afectarían la integridad del principal pulmón verde de la región, el Parque Pereyra Iraola y Reserva de Biósfera. La primera traza lo hace penetrando la reserva, en tanto que la segunda pasaría por la calle 403 de Villa Elisa, considerada por las leyes internacionales como una Reserva de la Biósfera, es decir una zona buffer o de amortiguación entre esta área protegida y el trazado urbano ${ }^{13}$.

\footnotetext{
12 La reforma del Código de Edificaciones fue sancionada por el Consejo Deliberante local en su sesión ordinaria del 14 de abril. Semanas después, el día 28 del mismo mes, es aprobada la ordenanza que introduce modificaciones al Código de Planeamiento Urbano. Para obtener mayores detalles acerca de los alcances de estas reformas ver las ediciones impresas de diario El Día del 11, 25 y 29 de abril del año 2010.

13 Para mayores detalles sobre la obra y sus trazas posibles ver: Dirección Nacional de Vialidad.(2010). Taquigrafía Audiencia Pública Construcción Autopista de Vinculación Juan Domingo Perón. Disponible en: http://www.vialidad.gov.ar/audiencias_publicas/audiencia_presidenteperon/TaquigraficaAudienciaPublica.pdf Consultada 15-12-2015; y Vecinos Autoconvocados de Villa Elisa (2011). "No a otra autopista en el Parque Pereyra Iraola ni en Villa Elisa. Informe General". Disponible en: http://vecinosvillaelisa.wordpress.com Consultada 15-12-2015.
} 


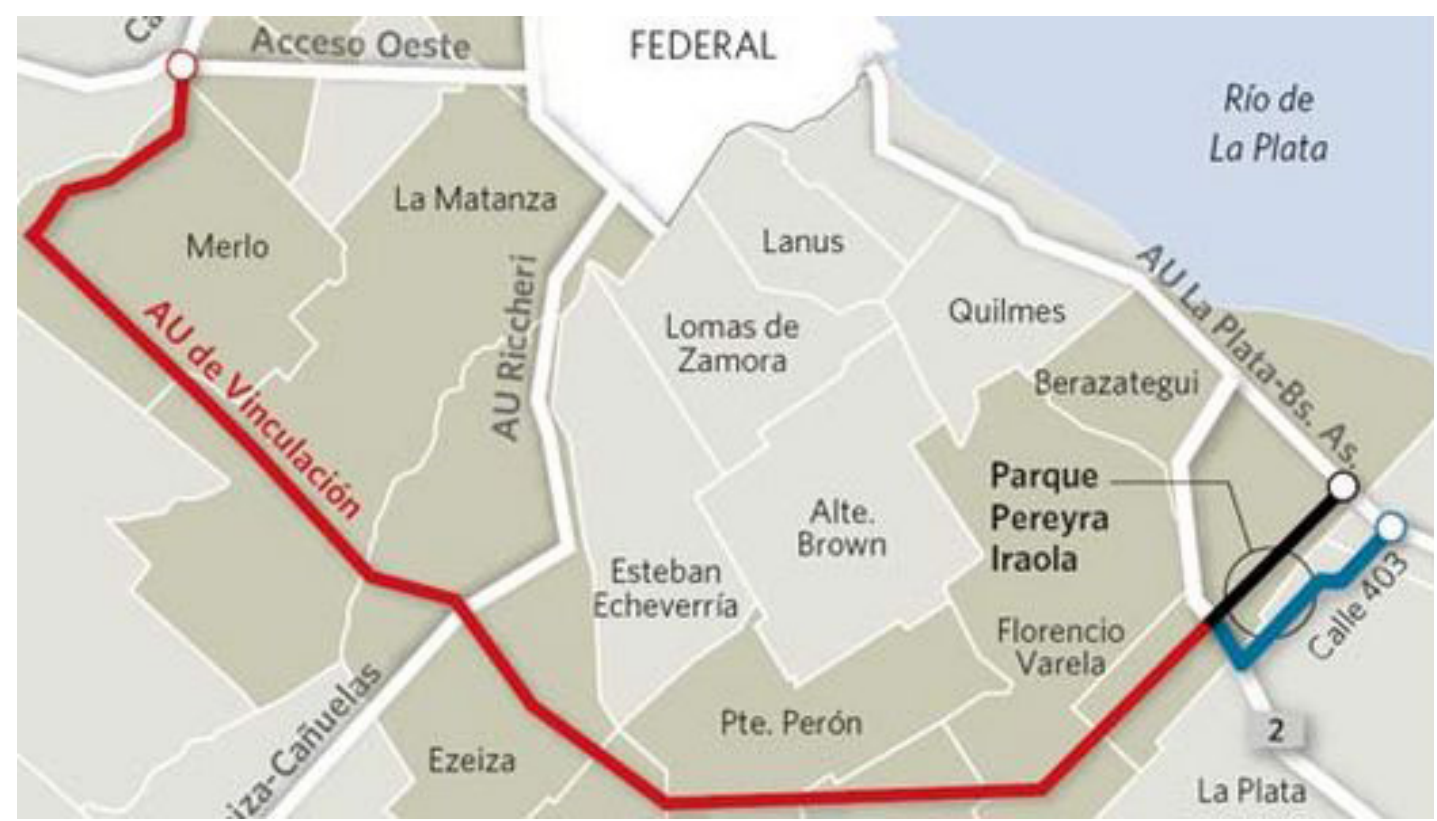

Primer y segunda alternativa para el Tramo IV de la Autopista Presidente Perón. La segunda traza presentada por la Dirección Nacional de Vialidad, propone conectar la Ruta 2 con la Autopista Buenos Aires-La Plata, construyendo el enlace vial sobre la calle 403 de la localidad de Villa Elisa. Fuente: sitio web Vecinos Autoconvocados de Villa Elisa. Fuente: vecinosvillaelisa.wordpress.com. Consultada: 15-03-1012.

Para comenzar a desarrollar los lazos que desde la organización se recrean, partimos por considerar que el término autoconvocados hace referencia a un procedimiento de autoadscripción por parte de sus integrantes. Esa adscripción refiere en una primera instancia a un territorio compartido que los une como vecinos. Es la identificación con una causa, exigencia o reivindicación la que motiva el acercamiento de las personas al movimiento, siendo el requisito fundamental y casi excluyente compartir el mismo territorio (Bonzi, 2010). En el caso de V.A.V.E ambas ideas se fusionan y son incluidas en el nombre que el grupo tomó como distintivo del colectivo.

Si se asume que el principal factor de unión del grupo autocovocado es un territorio compartido, la composición de los grupos deviene heterogénea en cuanto al poder adquisitivo de sus integrantes, sus niveles de instrucción, su vínculo con el problema a resolver, su actividad profesional, sus experiencias previas de participación, su ideología o militancia política. Esta heterogeneidad se manifiesta en V.A.V.E en la pluralidad de actores que conviven en la organización: quinteros productores, propietarios que temen por la expropiación de sus viviendas, profesionales que aportan los conocimientos desde sus disciplinas (técnicos, abogados, médicos, economistas), militantes sociales que participan en diversas instituciones de la comunidad y antiguos vecinos que temen que la autopista rompa el paisaje que los vio nacer, crecer y formar sus familias. 
Frente a la diversidad inicial que presenta la composición de sus actores, el grupo necesitó crear sus propios sentidos de pertenencia, en tanto representaciones y valores construidos colectivamente. Ese desafío comprendió en principio la creación de un universo compartido por sus miembros, en el cual resultó fundamental crear algunos acuerdos capaces de contemplar las necesidades del grupo emergente.

Las primeras aproximaciones realizadas en el inicio del trabajo de campo mediante técnicas de observación participante y diálogos inaugurales con los vecinos, demuestran que lo que inquieta y moviliza al grupo es la defensa de su territorio y su vida cotidiana, a la vez que se preocupan por la participación ciudadana la representación política de sus intereses y la política pública: “El medioambiente no está presente en la política de Estado, ni como problema en la sociedad, el problema ambiental es un problema de todos, hay que participar activamente en la defensa de nuestro medio y nuestro territorio", explicaba Norberto Filipi, vecino de Berazategui, durante una asamblea realizada en la localidad de Villa Elisa en noviembre del año 2010 momento inicial del conflicto. Asimismo, desde sus orígenes el grupo dejó en claro que "no estamos en contra ni de la autopista ni de un progreso sustentable. Simplemente estamos en contra de la autopista con un trazado irracional, por el Parque Pereyra Iraola y por la calle 403", expresaba Gabriel, representante del grupo autoconvocado. Posteriormente, Pablo, otro de los integrantes, concluía reforzando la idea:

\footnotetext{
No nos oponemos al progreso, no nos oponemos a la planificación regional racional. Pero para eso el Estado y las corporaciones deben respetar a todos y cada uno de los habitantes y salvaguardar nuestro hábitat y nuestro ambiente, que es de todos, como desafío para el siglo XXI.
}

En este marco, los propios vecinos afirman que "es importante una revisión del territorio y lo que significa para cada uno de los actores" (Toni, integrante de la Asamblea Parque Pereyra y Reserva de Biósfera).

Respecto de los reclamos que realizan las organizaciones sociales, Leiras (2007) propone que "la actividad política de las organizaciones de la sociedad civil incluye tanto la promoción de cambios como la resistencia a los cambios" (45). En el caso de Vecinos Autoconvocados de Villa Elisa no es posible afirmar que tomen una de estas dos posturas de manera pura. En este sentido, proponemos recuperar una mirada que permita aproximarnos a las prácticas sociales como procesos dialécticos que se juegan entre la conservación y la transformación. Los vecinos, en sus prácticas concretas, buscan reforzar 
políticas que apunten a la conservación de una ciudad que viven y recrean, pero al mismo tiempo, tejen estrategias renovadas de participación y disputa por la representación en los espacios de toma de decisiones.

Como podemos observar con Millán (1994) y profundizar con Reguillo (1999), V.A.V.E. cumple con las características de autodefinirse como una agrupación no políticopartidario, de lazos vecinales, de arraigo barrial, que goza de una dinámica de formación no instituida. Es más, una de sus banderas principales es la de asumir como derecho que nunca va a cumplir la condición de institución formal. Asimismo este grupo, nos permite observar, siguiendo a Williams (1997) procesos de reapropiación de espacios; del sentido de la protesta y de su canalización; y, de prácticas de construcción de ciudadanía.

\section{Conclusión}

Teniendo en cuenta que el trabajo que presentamos en este artículo aún se encuentra en proceso de indagación, en estos párrafos abordaremos estimaciones que se deben considerar como interrogantes a construir y problematizar más que aseveraciones cerradas. Con respecto a nuestra problemática central, las agrupaciones autoconvocadas son caracterizadas, mediante trabajos que abordan temáticas similares, como organizaciones no partidarias-gubernamentales que emergen del tejido urbano porque sus miembros se ven interpelados en el ejercicio de la ciudadanía, tal es el caso de V.A.V.E. que se nuclea frente a la imposición de la autopista en su trama barrial.

Es por ello que a lo largo del trabajo expusimos los marcos teóricos que utilizamos para asumir a las agrupaciones autoconvocadas como organizaciones independientes del Estado, gobierno o partidos políticos que a su vez tienen la característica de ser no instituidas. En este sentido, se tornan espacios de la trama urbana que surgen para canalizar la protesta social que no encuentra representación en las diferentes instituciones formales propuestas por el Estado, partidos políticos y/o sindicatos.

Sumada a estas características es importante poner énfasis que las agrupaciones analizadas se nuclean por cercanía, surgen del barrio pero en un estado de novedad, ya que no utilizan las instituciones formales como son los mencionados clubes sociales, aunque en sus prácticas canalizan muchas de las demandas que antaño se expresaban en estos espacios. En particular esta última caracterización abre la posibilidad de indagar sobre las 
novedosas formas de protesta social que, dado que en su mayoría vienen a ocupar lugares perdidos o abandonados, las consideramos como herederas de "modernas" instituciones barriales.

Como parte la propuesta de este artículo, expusimos las herramientas metodológicas que estamos utilizando para su análisis, resaltando la importancia de desarrollar perspectivas cualitativas para dimensionar procesos de construcción de la ciudadanía donde emergen conflictos y disidencias con el Estado, y sus múltiples dependencias, en sistemas que se inscriben cada día con mayor fuerza en tramas globales de construcción de poderes y saberes.

Expusimos que se privilegia la etnografía como principio organizador del trabajo de campo, poniendo en diálogo nuestros entrevistados/as con los documentos bibliográficos, hemerográficos y mediáticos que fuimos recabando - y continuamos haciéndolo- hasta el momento de redacción de este artículo. Todos estos elementos significaron los pilares del análisis interpretativo que, es importante señalar, tuvo en cuenta la perspectiva del actor desde sus múltiples prácticas y expresiones, más aún si se tiene en cuenta la importancia del factor emotivo que implica el encontrase sumergido en un conflicto social.

Desde el punto de vista del abordaje barrial, en estos momentos nos encontramos realizando la reconstrucción histórica del barrio, poniéndolo en tensión con el crecimiento de la región metropolitana de Buenos Aires (su aproximación y sentido de invasión), la construcción de apropiaciones del conflicto que realizan otros colectivos barriales (Asamblea Reserva de Biosfera Pereyra-Iraola) y las interpelaciones vecinales al municipio y al poder judicial. Todos elementos, que muestran la complejidad que implica el análisis de estos fenómenos de participación ciudadana en la trama urbana de nuestros barrios y ciudades.

Referencias Beck, U. (1998).¿Qué es la globalización? Falacias del globalismo, respuestas a la globalización. Barcelona: Paidós.

Bonzi, L. (2010). “Disputas territoriales en torno a la actividad minera en los Valles Calchaquíes, Salta. El caso de la mina Don Otto en el departamento de San Carlos". En El desarrollo y sus lógicas de disputa en territorios del norte argentino, pp. 197-219. Buenos Aires: Centro de Integración Comunicación Cultura y Sociedad. 
Cáneva, V. (2012). "En busca de categorías para el estudio de lazos urbanos: las Organizaciones autoconvocadas no partidario-gubernamentales". En Echeverría, M. y Vestfrid, P. (comp.) Aprender a investigar: Recorridos iniciales en comunicación, pp. 25-37. La Plata: Ediciones de Periodismo y Comunicación, Universidad Nacional de La Plata.

Cáneva, V. y Mendoza, H. (2007). Clubes platenses: al rescate de lo colectivo: Riesgos, desafíos y posibilidades de las instituciones barriales en la trama de la ciudad posmoderna (Tesis de grado). Universidad Nacional de La Plata, La Plata, Argentina.

Claps, L. y Colao, D. (2005). Comunicación, recursos naturales y comunidad en Esquel (Tesis de maestría). Universidad de Buenos Aires, Buenos Aires, Argentina.

Cossani, A. L. y Duffard, M. E. (2007). Reflexión y acción en la Asamblea Barrial de Villa Elisa (Tesis de grado). Universidad Nacional de La Plata, La Plata, Argentina.

Freidin, B. y Perrugoría, I. (2007). “Construyendo la identidad del movimiento asambleario en contextos políticos cambiantes una discusión teórico-metodológica”. En Sautu, R. (comp) Práctica de la investigación cuantitativa y cualitativa. Articulación entre la teoría, los métodos y las técnicas, pp 209247. Lumiere: Buenos Aires.

García-Canclini, N. (1990). Culturas Híbridas. Estrategias para entrar y salir de la modernidad. Grijalbo: México.

Grimson, A. (2008). "Buenos Aires neoliberalismo y después. Cambios socioeconómicos y respuestas populares". En Portes, A., Roberts, B. y Grimson, A. (ed.) Ciudades latinoamericanas. Un análisis comparativo en el umbral del nuevo siglo, pp. 19-147. Prometeo libros: Buenos Aires.

(2009). "Clasificaciones espaciales y territorialización de la política en Buenos Aires". En Grimson, A., Ferraudi, M. y Segura, R. (comps.). La vida política en los barrios populares de Buenos Aires (pp.11-38). Prometeo libros: Buenos Aires.

Guber, R. (2008). El salvaje metropolitano: reconstrucción del conocimiento social en el trabajo de campo. Buenos Aires: Paidós.

Harvey, D. (2004). La condición de la posmodernidad. Investigación sobre los orígenes del cambio cultural. Buenos Aires: Amorrortu.

Kessler, G. y Di Virgilio, M. (2008). “La nueva pobreza urbana: dinámica global, regional y Argentina en la últimas dos décadas". Revista CEPAL, 95, 31-50.

Leiras, M. (2007). "La incidencia de las organizaciones de la sociedad civil en las políticas públicas", pp. 17-65. En Acuña, C. y Vaccheri, A. (comps.) La incidencia política de la sociedad civil. Buenos Aires: Siglo XXI editores.

Lewkowicz, I. (2004). Pensar sin estado. La subjetividad en la era de la fluidez. Buenos Aires: Paidós.

Martín-Barbero, J. (1987). De los medios a las mediaciones. Gilli: México.

Millán, R. (1994). "Solidaridad y Producción informal de recursos". En Millán, R (ed.) Solidaridad recurso o valor, pp. 65-75. México: Universidad Nacional Autónoma de México.

Piovani, J. (2007). "El diseño de la investigación". En Marradi, A., Archenti, N. y Piovani, J. (comps.). (comp.). Metodologías de las ciencias sociales. Buenos Aires: Emecé. 
Ramos, J. (1997). "Un balance de las reformas estructurales neoliberales en América Latina". Revista CEPAL, 62, 15-38.

Pírez, P. (1995). "Actores sociales y gestión de la ciudad". Ciudades, 28. Disponible en: http://www.cedet. edu.ar/Archivos/Bibliotecas/pirez_actores.pdf..

Reguillo, R. (1999). La construcción simbólica de la ciudad. Sociedad, desastre y comunicación. Instituto Tecnológico y de Estudios Superiores de Occidente: México.

Rosboch, M. E. (2006). La rebelión de los abrazos. Tango, milonga y danza. La Plata: Editorial de la Universidad Nacional de La Plata.

Rosboch, M. E. y Cáneva, V. (2010). "Entre la movilidad y la institución. Espacios urbanos que potencian el compromiso cívico político". XII Congreso REDCOM Los desafíos del periodismo y la comunicación en el Bicentenario. Mendoza, Argentina.

Santos, M. (2000). "El territorio, un agregado de espacios banales”. Boletín de Estudios geográficos, 17, 87-96.

Sidicaro, R. (2004). "Los nuevos caleidoscopios urbanos". TODAVÍA, 9, 33-37.

Svampa, M. y Sola, M. (2010). "Modelo minero, resistencias sociales y estilos de desarrollo: los marcos de la discusión en Argentina”. Ecuador Debate, 79, 105-126.

Torrico, E. (2004). Abordajes y períodos de la teoría de la Comunicación. Santafé de Bogotá: Norma.

Weinstock, A. M. (2012). Sí a la vida; No a la Mina. Voces y acciones confrontando el modelo de desarrollo en Patagonia (tesis de Maestría). Universidad de Buenos Aires, Buenos Aires. Argentina.

Williams, R. (1997). Marxismo y Literatura. Barcelona: Península.

Cómo citar Cáneva, V. (2016). “Ciudad y participación vecinal: abordajes teórico-metodológicos para el análisis de organizaciones autoconvocadas". Comunicación y Medios, 25 (33), 115 - 137. 